\title{
$\beta 1$ integrin signaling in asymmetric migration of keratinocytes under mechanical stretch in a co-cultured wound repair model
}

\author{
Dongyuan Lü1,2,3, Zhan Li ${ }^{1,2,3}$, Yuxin Gao ${ }^{1,2,3}$, Chunhua Luo ${ }^{1,2,3}$, Fan Zhang ${ }^{1,2,3}$, Lu Zheng 1,2,3, Jiawen Wang ${ }^{1,2,3}$, \\ Shujin Sun ${ }^{1,2,3}$ and Mian Long ${ }^{1,2,3^{*}}$
}

*Correspondence:

mlong@imech.ac.cn

${ }^{1}$ Center of Biomechanics

and Bioengineering, Institute

of Mechanics, Chinese

Academy of Sciences,

Beijing 100190, China

Full list of author information

is available at the end of the

article

\begin{abstract}
Background: Keratinocyte $(\mathrm{KC})$ migration in re-epithelization is crucial in repairing injured skin. But the mechanisms of how mechanical stimuli regulate the migration of keratinocytes have been poorly understood.

Methods: Human immortalized keratinocyte $\mathrm{HaCaT}$ cells were co-cultured with skin fibroblasts on PDMS membranes and transferred to the static stretch device developed in-house for additional 6 day culture under mechanical stretch to mimic surface tension in skin. To detect the expression of proteins on different position at different time points and the effect of $\beta 1$ integrin mechanotransduction on $\mathrm{HaCaT}$ migration, Immunofluorescence, Reverse transcription-polymerase chain reaction, Flow cytometry, Western blotting assays were applied.
\end{abstract}

Results: Mechanical receptor of $\beta 1$ integrin that recognizes its ligand of collagen I was found to be strongly associated with migration of $\mathrm{HaCaT}$ cells since the knockdown of $\beta 1$ integrin via RNA silence eliminated the key protein expression dynamically. Here the expression of vinculin was lower but that of $\mathrm{Cdc} 42$ was higher for the cells at outward edge than those at inward edge, respectively, supporting that the migration capability of keratinocytes is inversely correlated with the formation of focal adhesion complexes but positively related to the lamellipodia formation. This asymmetric expression feature was further confirmed by high or low expression of PI3K for outward- or inward-migrating cells. And ERK1/2 phosphorylation was up-regulated by mechanical stretch.

Conclusion: We reported here, a novel mechanotransduction signaling pathways were $\beta 1$ integrin-dependent pattern of keratinocytes migration under static stretch in an in vitro co-culture model. These results provided an insight into underlying molecular mechanisms of keratinocyte migration under mechanical stimuli.

Keywords: Keratinocyte, Mechanical stretch, Fibroblast, $\beta 1$ integrin, Mechanotransduction

\section{Background}

Wound healing is an intricate process in which the skin repairs itself with a series of sequential cellular and biochemical events after injury [1]. It is usually divided into three or four sequential yet overlapping phases, including hemostasis, inflammation, granulation tissue formation and re-epithelialization, matrix formation and remodeling $[2,3]$. 
All of these phases are highly coordinated physiological processes and require dynamic, coordinated intercommunication among different type cells in specific tissue regions. Keratinocytes are recognized to regulate evidently wound repairing through cell migration, proliferation and differentiation, especially in the crucial step of re-epithelialization $[1,4]$. Re-epithelization is a key procedure during wound repairing where keratinocytes migrate asymmetrically to cover the wound bed prior to cell proliferation in a few hours after wounding [5]. Currently, keratinocyte migration dynamics acts as an excellent model for elucidating the wound healing both in vivo and in vitro.

It has been well known that keratinocyte migration dynamics is highly manipulated by their host microenvironment $[1,6]$. On a hand, biochemical signaling is crucial to cell migration, including the intercommunication with other dermal cells, extracellular matrix (ECM), or growth factors and cytokines produced by fibroblasts [1]. Distinct constituents of ECM have different effects on keratinocyte migration velocity and motility [7-9]. Specifically, type I collagen, as one of main ECM components in wound site, plays a crucial role in modulating keratinocyte migration [2]. On the other hand, mechanical signaling is also an important factor in wound repairing because the configuration and function of regenerative tissue depends on skin contraction. For example, the contractile activity can be enhanced between keratinocyte and fibroblast interactions under mechanical tension [10]. Mechanical forces derived from tissue development and remodeling regulate the synthesis of various ECM components and speed the wound healing progress $[11,12]$. Keratinocyte migration mediated by collagen I involves in the binding of cell surface adhesive receptors to matrix proteins in which mechanical forces play a crucial role in modulating the de novo synthesis of collagens. Clinically, although the topical suction pressure therapy, vacuum-assisted closure (VAC), has been known as an effective, widely-applied technique to promote various chronic wounds healing [13, 14], it is still unclear why the mechanical forces derived by suction pressure is beneficial in the VAC therapy at cellular as well as molecular levels [15]. Previously, we found that $\mathrm{HaCaT}$ tends to migrate asymmetrically under mechanical stretch in the presence of fibroblast co-culture, which is mainly mediated by EGF in a paracrine manner [16]. However, the underlying mechanisms in intracellular signaling remain unknown.

To date, cell mechanotransduction is known to be a well-defined process to translate extracellular mechanical signals into intracellular biochemical events. For example, a mechanical receptor of $\beta 1$ integrin expressed on keratinocyte surface (e.g., $\alpha 2 \beta 1$, and $\alpha 3 \beta 1)$ is able to sense the mechanical signals via binding to the surrounding collagen I $[17,18]$. There is growing evidence to support that $\beta 1$ integrin is a key adhesive molecule in de novo focal contact formation, keratinocyte migration, and re-epithelization of wound tissue $[19,20]$. Migratory capacity of $\beta 1$-deficient keratinocytes is strongly impaired in vitro and epithelial migration is dramatically reduced in wound healing in $\beta 1$-integrin null mice [20]. Although $\beta 1$ integrin is a well-known mechanosensor for various types of cells, little is known about its roles in keratinocyte mechanotransduction mechanisms as well as the underlying transduction pathways [21, 22]. Not only the so-called "outside-in" signaling induces the formation of focal adhesion complex (FAC) and the remodeling of actin polymerization, but it also activates the downstream phosphorylation cascade of intracellular stretch-sensitive proteins and the expression of mechanically-sensing genes to regulate a variety of cellular functions, such as cell 
migration [23]. For example, integrins regulate various protein kinases (e.g., tyrosine kinase, phosphatase, and mitogenesis-associated protein kinase or MAPK) in cell proliferation and other processes [21, 24]. As a key signaling molecule in MAPK pathway, extracellular-signal-regulated kinase (ERK1/2) activation is specifically required in epithelial cell migration where ERK1/2 pathway coordinates the dynamics of wound healing and the inhibition of ERK1/2 delays the process of wound healing [25]. Moreover, ERK1/2 also plays a crucial role in mediating cellular responses to mechanical stretch. Combined with the phosphatidylinositol-3-OH kinases (PI3Ks) that serve as the mediators of integrin-induced cytoskeletal remodeling and cell migration [26, 27], the other small GTPases, such as Cdc42, regulate actin polymerization in a collagenous matrix and modulate the motility and invasion of epithelial cells in a PI3K-dependent pathway [28]. Thus, it is important to elucidate the underlying pathways of $\beta 1$ integrin-induced keratinocytes migration under mechanical stimuli.

Together, the challenging issues for mechanotransduction mechanisms of keratinocytes migration in cutaneous wounds mainly rely on: Whether does mechanical stretch modulate dynamically the expression of key signaling proteins and how do the cells sense the mechanical signals? Whether do the other signaling factors affect the migration of keratinocytes and what are the potential mechanotransduction mechanisms? Here we developed an in vitro static stretch approach to quantify the mechanicallyinduced proteins expression of human keratinocytes on substrate coated by collagen I and in the presence of human fibroblasts. Mechanotransduction mechanisms of $\beta 1$ integrin-mediated signaling pathway were determined. Our results provided the insight into the mechanotransduction pathways in manipulating keratinocyte migration under static stretch, which implies potential application in clinical treatment of wound repairing.

\section{Methods}

\section{Cell lines and reagents}

Human immortalized keratinocyte HaCaT cell line CRL2309 and human skin fibroblast (HF) cell line CRL2088 were obtained from American Type Culture Collection (ATCC, Rockefeller, USA). HaCaT cells were grown in RPMI 1640 medium (Hyclone, Utah, USA) with $10 \%$ fetal bovine serum (FBS, Gibco, Grand Island, USA) and $1 \%$ penicillin/streptomycin (Hyclone, Utah, USA). Fibroblasts were cultured in Dulbecco's Modified Eagle's medium (DMEM, 1 g/liter glucose) with 10\% FBS and 1\% antibiotics. Cells were dissociated using 0.05\% trypsin and 0.02\% EDTA in phosphate-buffered saline (PBS, pH 7.4) when they are approximately $85-90 \%$ confluent, and moved to the static stretch device developed in-house for additional 6 day culture under mechanical stretch (Fig. 1a) [16]. Cells were detected at different time points for functional measurements of mechanotransduction pathways.

Mouse-anti-human anti- $\beta 1$ integrin monoclonal antibodies (mAbs) for flow cytometry and western blotting (WB), anti- $\beta$-actin $\mathrm{mAb}$ for WB, anti-Cdc42, anti-PI3K, and anti-phosphorylated $(p-)$ ERK1/2 mAbs as well as goat-anti-human polyclonal antibody against vinculin for immunofluorescence (IF) staining, were obtained from Santa Cruz Biotechnology (Dallas, Texas, USA). Alexa Fluor-conjugated secondary mAbs (Sigma-Aldrich, Missouri, Saint Louis, USA) for IF staining and HRP-conjugated secondary mAbs (Boster, Wuhan, Hubei, China) for WB analysis were obtained. Coverslips 

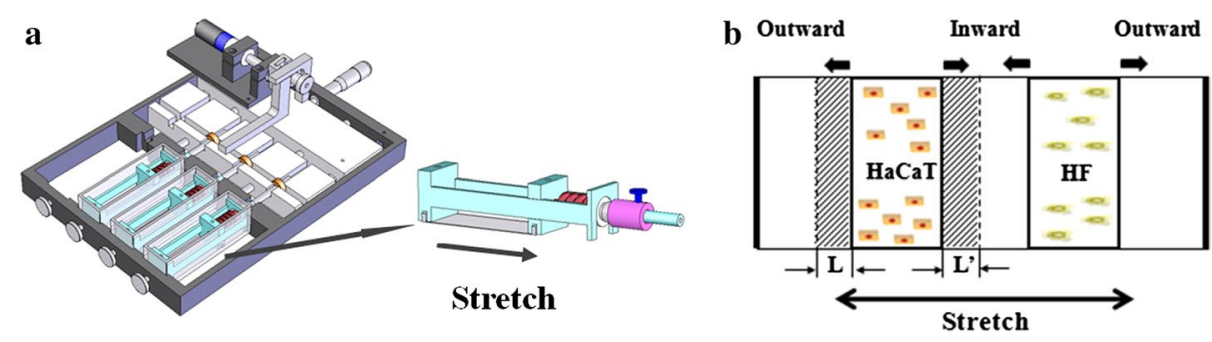

Fig. 1 Mechanical stimuli used to examine signaling proteins in $\mathrm{HaCaT}$ cells migration. a Image of an inhouse developed static stretch device by applying mechanical stimuli via a stretchable silicone membrane to the cells. b Schematic of cell migration under tensile stress on silicone membrane at a typical $20 \%$ strain. $\mathrm{HaCaT}$ and $\mathrm{HF}$ cells were seeded in two separated regions, and the migration distance L (away from HF cells) or L'(towards HF cells) and the migration leading edge of HaCaT cells were illustrated

and paraformaldehyde were purchased from Fisher Scientific (Somerville, Massachusetts, USA). Hygromycin B was from Roche (Baden-Wuerttemberg, Mannheim, Germany). Acid-soluble bovine achilles tendon-derived collagen I (cell matrix type I-A), bovine serum albumin (BSA), and sodium dodecyl sulfate (SDS) were obtained from Sigma-Aldrich.

\section{Cells migration}

To detect the dynamics of protein expression at the migration leading edge of $\mathrm{HaCaT}$ cells inwardly (between two cell zones) or outwardly (away from two cell zones) directed to co-cultured fibroblasts, cells (keratinocytes or fibroblasts) seeding and migration were performed as described previously [16]. To exclude the possible impacts of cell proliferation on migration dynamics of $\mathrm{HaCaT}$ cells, both types of cells were pre-incubated with a conventional cell proliferation inhibitor (mitomycin $\mathrm{C}$ at $10 \mu \mathrm{g} / \mathrm{ml}$ for $2 \mathrm{~h}$ ) prior to seeding them onto silicone membrane and exerting mechanical stretch [16]. Mitomycin $\mathrm{C}$-treated $\mathrm{HaCaT}$ or $\mathrm{HF}$ cells grown in a flask were transferred onto silicone membrane pre-coated by collagen I in $0.15 \mathrm{mg} / \mathrm{ml}$ at $37{ }^{\circ} \mathrm{C}$ for $2 \mathrm{~h}$ or treated by oxygenized plasma as a control. To mimic the distributions of the two types of cells in separated regions in wound repair, HF cells were put only on one side of $\mathrm{HaCaT}$ cells. Nontoxic stainless steel frames were used retained the cells inside the seeding zone. The membrane was then mounted to the stretch device and experienced a steady stretch of $20 \%$ strain for 6 days to the $\mathrm{HaCaT}$ and $\mathrm{HF}$ co-culture (Fig. 1b). $\mathrm{HaCaT}$ and $\mathrm{HF}$ cells were seeded at respective density of $5 \times 10^{5}$ cells $/ 0.8 \mathrm{~cm}^{2}$ and $1 \times 10^{5}$ cells $/ 0.8 \mathrm{~cm}^{2}$. Optical images of cell migration leading edge were monitored using a CCD-camera at the particular time point.

\section{IF staining}

To quantify the time course of the expressions of vinculin, Cdc42, PI3K and phosphorylated ERK1/2 in $\mathrm{HaCaT}$ cells under co-cultured and mechanical stretch, $\mathrm{HaCaT}$ cells adhering on the silicone membrane at different time points were fixed with $4 \%$ paraformaldehyde in PBS for 15 min, permeated with $0.2 \%$ Triton X-100 for $4 \mathrm{~min}$, and blocked by $1 \%$ BSA for $30 \mathrm{~min}$ at room temperature. The cells were then incubated with relevant primary antibodies, respectively, for $1 \mathrm{~h}$ at $37^{\circ} \mathrm{C}$ or overnight at $4{ }^{\circ} \mathrm{C}(1: 100$ dilution in 1\% BSA). After washing, rhodamine-conjugated second antibody was added in for additional $45 \mathrm{~min}$ incubation at room temperature. A coverslip was mounted onto 
silicone membrane in FluoPrep mounting medium (Dako, Trappes, France) and the cells locating at the leading edge of migration zone were visualized by a Tcs sp5 Leica confocal laser microscope (Leica, Cambridge, UK). Fluorescent images were captured for $\sim 20$ cells in one frame and totally three frames in each case. Image analysis was done using by ImageJ 1.41 software (National Institutes of Health, Bethesda, USA) to calculate the fluorescent intensity of the stained individual cells by setting a threshold. Normalized mean fluorescence intensity (FI) was used to indicate the relative fluorescent intensity of detected proteins.

\section{RNA interference of $\beta 1$ integrin in $\mathrm{HaCaT}$}

pSilencer hygro plasmid (Ambion, Austin, TX, USA) was used for DNA vector-based RNA interference. The $\beta 1$ integrin RNAi plasmid was structured based on pSilencer hygro plasmid (Plasmids as the gift from Dr. Xiangdong Luo, Third Military Medical University). RNA interference experiments were carried out using commercial reagent upon the manufacturer's instructions. Briefly, the RNAi plasmids were transfected into $\mathrm{HaCaT}$ cells using Lipofectamine ${ }^{\mathrm{TM}} 2000$ reagent (Invitrogen, Carlsbad, USA) in 1-2 $\mu \mathrm{g}$ of expression plasmid in a 6 well plate with serum-free medium. After $6 \mathrm{~h}$ of transfection, the medium was replaced by serum-containing medium and incubated for $48 \mathrm{~h}$. Collected cells were then grown in the medium of RPMI 1640 containing hygromycin B $(80 \mu \mathrm{g} / \mathrm{ml})$ to enrich the successfully-transfected cells and to select the cell subpopulation expressing stably the target siRNA. Stably-silenced $\beta 1$ integrin $\mathrm{HaCaT}$ cell population was then cultured in standard condition $\left(37^{\circ} \mathrm{C}\right.$ with $\left.5 \% \mathrm{CO}_{2}\right)$ with hygromycin $\mathrm{B}$ $(80 \mu \mathrm{g} / \mathrm{ml})$ supplied in medium. Culture medium was exchanged each 3 or 4 days, and the knockdown efficiency of $\beta 1$ integrin expression after 21-day cell culture was confirmed by WB, RT-PCR, and flow cytometry tests. Negative and positive controls were designed to exclude the nonspecific effects.

\section{WB assay}

To detect the knockdown efficiency of $\beta 1$ integrin in $\mathrm{HaCaT}$, cells were harvested and lysed with ice-cold modified RIPA buffer (50 mM Tris-Cl at pH 7.4, 1\% NP40, $150 \mathrm{mM}$ $\mathrm{NaCl}, 1 \mathrm{mM}$ EDTA, $1 \mathrm{mM}$ PMSF, $1 \mathrm{mM} \mathrm{Na} \mathrm{VO}_{4}, 1 \mathrm{mM}$ phosphatase inhibitors, and $5 \mathrm{mg} / \mathrm{ml}$ each of aprotinin, leupeptin, and pepstatin). After being sonicated for $30 \mathrm{~s}$, lysates were maintained on ice for $30 \mathrm{~min}$, boiled for $5 \mathrm{~min}$ and then clarified by centrifugation for $10 \mathrm{~min}$ at $12,000 \mathrm{~g}$. Collected supernatant was used for WB analysis and protein concentrations were determined using a BCA protein assay kit (Pierce, Rockford, USA) with BSA as a standard. Briefly, same amounts of proteins were separated by electrophoresis on SDS-polyacrylamide gel and electroblotted onto nitrocellulose (NC) filters. Both the NC membranes and the blots were blocked with TBS-T (10 mM Tris-Cl at $\mathrm{pH}$ 8.0, $150 \mathrm{mM} \mathrm{NaCl}, 0.05 \%$ Tween-20) containing $5 \%$ nonfat dried milk for $>1 \mathrm{~h}$ at room temperature. Anti- $\beta 1$ integrin and anti- $\beta$-actin mAbs were added in and incubated overnight at $4{ }^{\circ} \mathrm{C}$ and washed three times in TBS-T, respectively. Protein blots were then incubated with a HRP-conjugated secondary $\mathrm{mAb}$ for $1 \mathrm{~h}$ at room temperature and visualized on X-ray films using enhanced chemiluminescence (Amersham Pharmacia Biotech, Piscataway, USA). $\beta 1$ integrin in wild-type $\mathrm{HaCaT}$ was detected as the positive control. 


\section{RT-PCR}

RT-PCR was performed to screen the HaCaT cell clones with stable knockdown of $\beta 1$ integrin. Total RNA was extracted using RNAiso Plus and subjected to reverse transcription into cDNA using PrimeScript 1st Strand cDNA synthesis Kit (TAKARA, Dalian, China). Briefly, $1 \mu \mathrm{g}$ of RNA was reverse transcribed using oligo (dT) as primer in a total volume of $25 \mu \mathrm{l} .5 \mu \mathrm{l}$ of cDNA solution was used to amplify specific transcripts by PCR. For semi-quantitative PCR of $\beta 1$ integrin, amplification of both $\beta 1$ integrin (Accession: BC020057.1) and $\beta$-actin genes (Accession: X00351.1) were conducted in the same tube. Regular PCR was done using Taq polymerase on the following primers $5^{\prime}$-GGA AAA CGG CAA ATT GTC AG-3' and 5'-TTG GGG TTG CAC TCA CAC AC-3' for amplification of $\beta 1$ integrin (600 bp), and 5'-CGT GGA CAT CCG CAA AGA C-3' and 5'-CTG CTG TCA CCT TCA CCG TTC-3' for amplification of $\beta$-actin (441 bp) for 35 cycles $\left(94{ }^{\circ} \mathrm{C}\right.$ for $5 \mathrm{~min}, 30$ cycles at $94{ }^{\circ} \mathrm{C}$ for $30 \mathrm{~s}, 55^{\circ} \mathrm{C}$ for $30 \mathrm{~s}, 72{ }^{\circ} \mathrm{C}$ for $30 \mathrm{~s}$ ) and finally extension at $72{ }^{\circ} \mathrm{C}$ for $7 \mathrm{~min}$. The products were then visualized by $1.5 \%$ agarose gel electrophoresis and subsequent ethidium bromide staining.

\section{Flow cytometry}

Monolayer $\mathrm{HaCaT}$ cells were harvested and neutralized by adding medium containing FBS. After being washed twice in PBS, the suspension of $\mathrm{HaCaT}$ cells was incubated with anti- $\beta 1$ integrin $\mathrm{mAb}$ in $1 \mu \mathrm{g}$ per $1 \times 10^{6}$ cells for $1 \mathrm{~h}$ on ice, and subsequently labeled with fluorescein-conjugated secondary antibody for $45 \mathrm{~min}$ on ice (1:500 dilution). After washing three times in PBS, collected cells were tested using a FACSCalibur machine (Becton-Dickinson, San Jose, USA) and the data were analyzed using FACSDiva software.

\section{Data analysis}

All data were collected from at least triplet measurements and presented as mean \pm standard error (SE). Analysis of variance (ANOVA) was used to compare the differences among various groups, and Student $t$ test was employed to compare the difference between two groups. $P$ value indicates the level of statistical significance of differences in the normalized distance or fraction. Tests that produce $P<0.01$ were considered to be significant.

\section{Results}

\section{$\beta 1$ integrin mediates $\mathrm{HaCaT}$ migration}

The cascade of cell migration includes the cell adhesion to ECM, the formation of FACs, and the remodeling of actin cytoskeleton, in which $\beta 1$ integrin is thought to be an important mechanical receptor in retaining the directed trajectory of keratinocyte migration [29]. To identify the impact of $\beta 1$ integrin on keratinocyte migration, we knocked down its expression by transfecting a $\beta 1$ integrin-pSilencer plasmid into $\mathrm{HaCaT}$ cells (named as Sil-HaCaT) when a mock plasmid served as a control. The efficiency of $\beta 1$ integrin knockdown in stably-transfected $\mathrm{HaCaT}$ cells was tested using semi-quantitative PCR analysis at RNA level (Fig. 2a), WB test (Fig. 2b) and flow cytometry analysis (Fig. 2c) at protein level. These results confirmed that the expression of $\beta 1$ integrin was high in wildtype (WT) HaCaT but quite low in Sil-HaCaT cells. To further understand the role of $\beta 1$ 
integrin in the dynamics of $\mathrm{HaCaT}$ migration, we compared the time course of $\beta 1$ integrin expression of WT- (Fig. 2d) and Sli- (Fig. 2e) HaCaT cells at both the leading edges under co-cultured and mechanical stretch. On one hand, the expression under stretch was enhanced in WT-cells at both the outward (squares) and inward (diamonds) leading edges at $1 \mathrm{~h}$ followed by a reduction down to the baseline level for up to $144 \mathrm{~h}$, suggesting that the up-regulation of $\beta 1$ integrin expression under mechanical stretch exhibited a rapid transition phase and no differences were observed between outward and inward migration of $\mathrm{HaCaT}$ cells. By contrast, the expression under non-stretch monotonically decreased with time and again no differences were observed between outward (cycles) and inward (triangles) migration (Fig. 2d). This time-lapsed declination of MFI per unit area is simply because the spreading area of those cells at leading edge keep increasing with time when $\beta 1$ integrin expression tends to be stable at sufficiently long time. On the other hand, the stretch-induced rapid up-regulation of $\beta 1$ integrin expression found for WT-cells was no longer present in Sil-cells, supporting that $\beta 1$ integrin is the mechanical receptor to sense the static stretch. Here no significant difference in normalized MFI was observed for $\mathrm{C} / \mathrm{N}$ OUT case between 0 and $1 \mathrm{~h}$ even though mean value at $1 \mathrm{~h}$ was slightly higher $(1.00 \pm 0.07$ vs. $1.42 \pm 0.16, P=0.077)$, which is likely attributed to very limited spreading of $\mathrm{HaCaT}$ cells within $1 \mathrm{~h}$ and quite low expression of $\beta 1$ integrin in

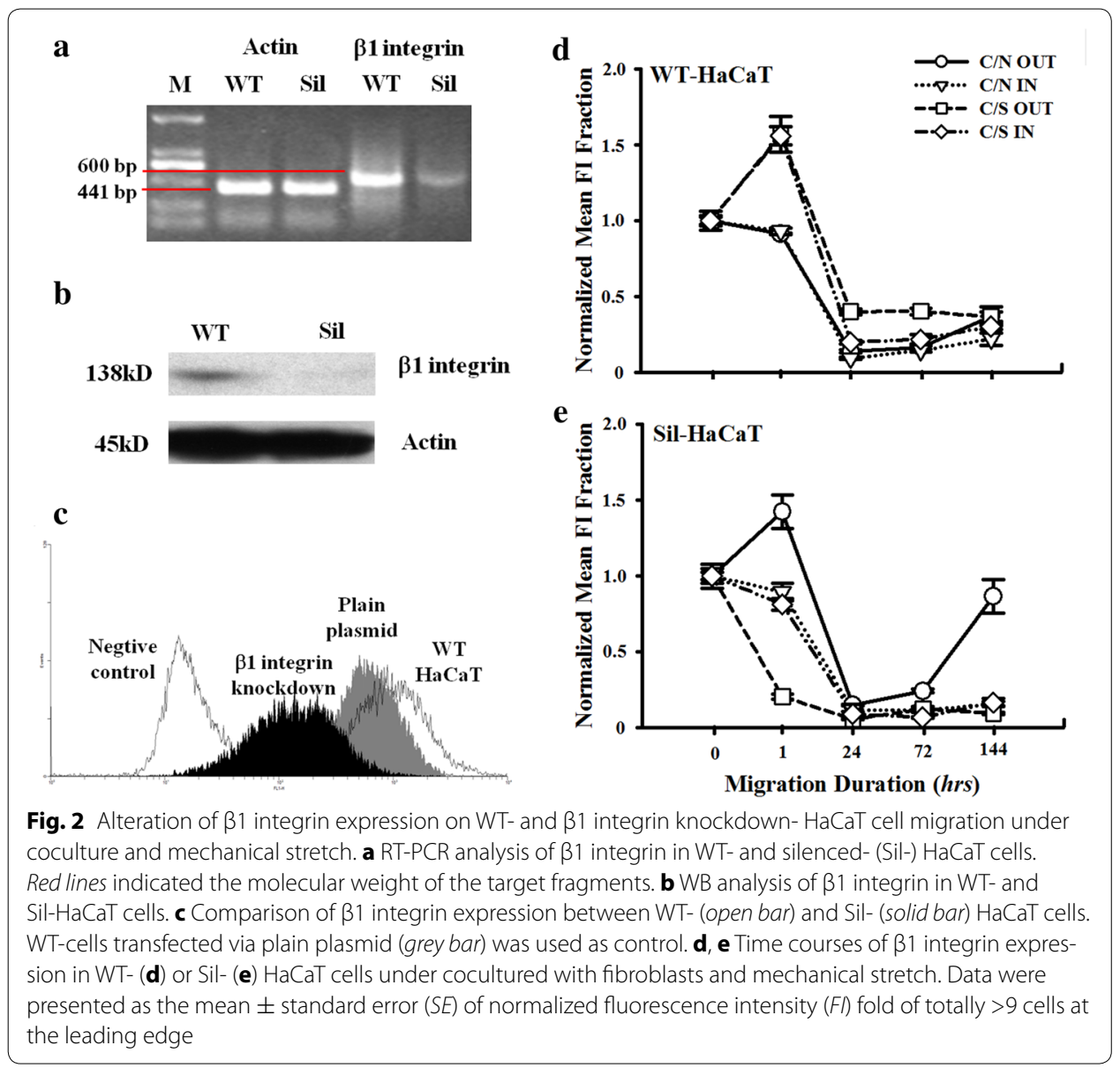


Sil-HaCaT cells. Meanwhile, slight differences between outward (squares or cycles) and inward (diamonds or triangles) leading edges were found under stretch or non-stretch (Fig. 2e), presumably attributed to the mechanical and/or biochemical sensing of other surface receptors rather than $\beta 1$ integrin since the absolute $\beta 1$ integrin expression was quite low in Sil-HaCaT cells. Together, these results indicated $\beta 1$ integrin serves as a mechanical receptor to translate the extracellular mechanical signals into intracellular biochemical events in a rapid response even though no visible differences of $\beta 1$ integrin expression were found between the two leading edges, suggesting that $\beta 1$ integrin is the key regulator of mechanical signals to alter the magnitude and pattern of $\mathrm{HaCaT}$ migration on collagen I-coated substrate.

\section{Vinculin plays pivotal roles in $\mathrm{HaCaT}$ migration}

Outside-in signaling via $\beta 1$ integrin-collagen I interactions activates the formation of FACs that possesses the mechanical resistance to the applied stretch. Since vinculinassociated focal contacts are thought to be in migratory phenotype and $\beta 1$ integrin is able to anchor to the FACs via its cytoplasmic tail [30-33], we next tested the impact of vinculin expression on $\mathrm{HaCaT}$ migration. For co-cultured WT-HaCaT cells, time course of vinculin expression under stretch exhibited an ascending phase when $t<24 \mathrm{~h}$ followed by a descending phase and presented a declined phase without stretch. Interestingly, vinculin expression at the outward leading edge (squares) was dramatically lower than that at the inward edge (diamonds) under mechanical stretch (e.g., $P=0.0014$ at $t=1 \mathrm{~h}$ ), indicating that $\mathrm{HaCaT}$ cells prefer to migrate to the outward end due to the down-regulation of vinculin as well as FACs. By contrast, no differences were found at the inward (triangles) and outward (cycles) edges under non-stretch (e.g., $P=0.829$ at $t=1 \mathrm{~h}$ ), all of which were significantly lower than those under stretch, respectively (Fig. 3a, b). These results indicated that the up-regulation of vinculin expression of co-cultured $\mathrm{HaCaT}$ cells is mechanically-dependent and that the asymmetric presentation of vinculin molecules is positively correlated with the asymmetric migration under stretch. Conversely, no differences of vinculin expression were observed at the inward and outward edges when the Sil-HaCaT cells were co-cultured with HF cells under stretch (Fig. 3c, d), suggesting that the function of vinculin is well correlated with that of $\beta 1$ integrin.

\section{Cdc42 is important in $\mathrm{HaCaT}$ migration}

We further tested if Rho family GTPase, particularly Cdc42, is involved in $\beta 1$ integrinmediated $\mathrm{HaCaT}$ migration since they are key regulators of cell motility, contractility, and migration through the linkage between integrins and cytoskeletal proteins [34, 35]. Similarly, time course of Cdc42 expression of co-cultured WT-HaCaT cells under stretch exhibited a rapid increase up to $t=1 \mathrm{~h}$ followed by a descending phase. And the expression at the outward edge (squares) was higher than that at the inward edge (diamonds) (e.g., $P=0.000045$ at $t=1 \mathrm{~h}$ ), indicating that $\mathrm{HaCaT}$ cells prefer to form the lamellipodia at the outward end due to the up-regulation of Cdc42 molecules [36]. By contrast, no significant differences were found at the inward (triangles) and outward (cycles) edges without stretch (e.g., $P=0.141$ at $t=1 \mathrm{~h}$ ) (Fig. $4 \mathrm{a}, \mathrm{b})$. These results indicated that the mechanically-dependent up-regulation of Cdc42 expression at the outward edge of cocultured $\mathrm{HaCaT}$ cells, which is favorable to cell spreading, is positively correlated with 


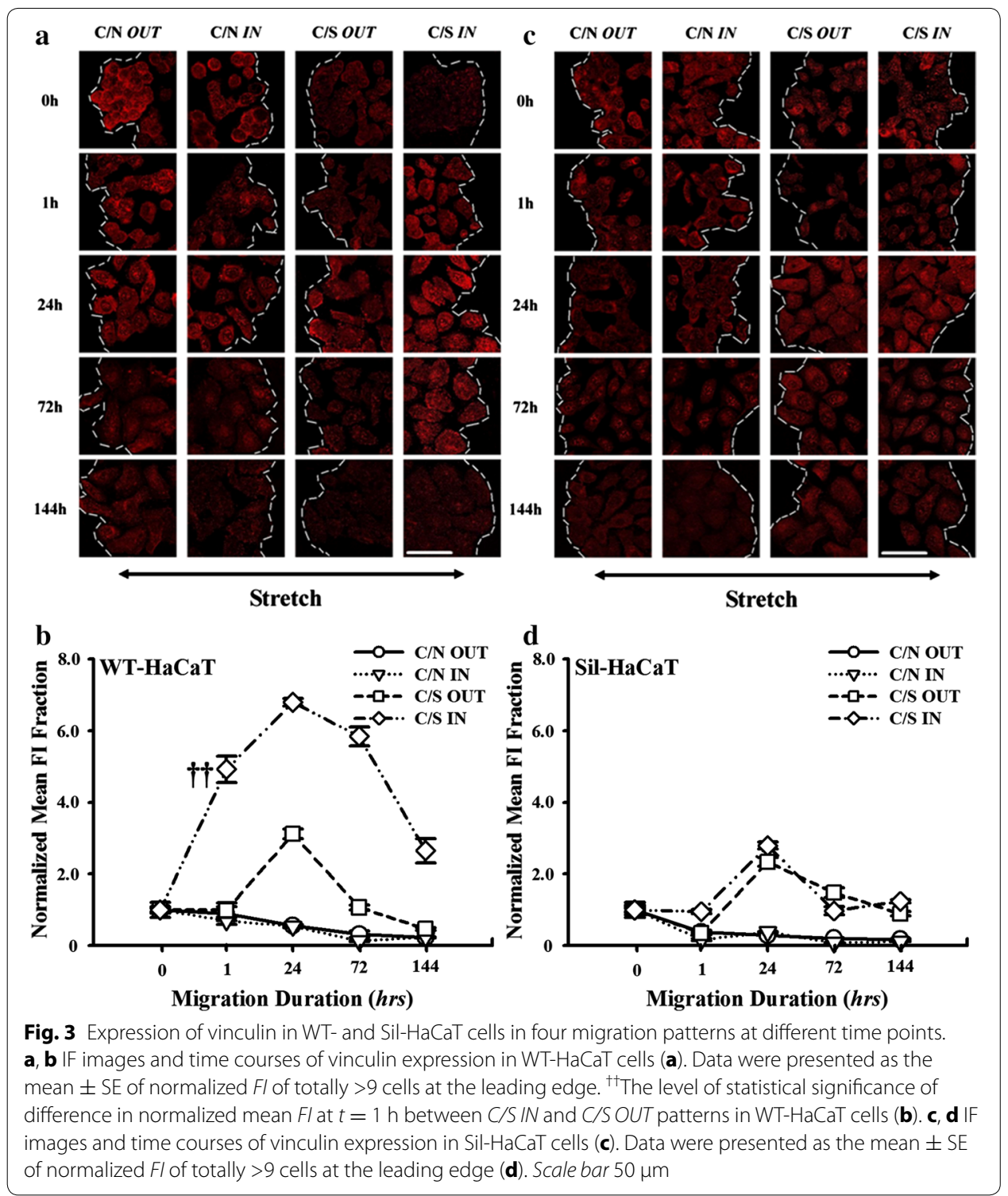

the asymmetric migration under stretch. Conversely, no differences of Cdc42 expression were observed at the inward and outward edges when the Sil-HaCaT cells were co-cultured with HF cells under stretch (Fig. 4c, d), suggesting that the function of Cdc42 is well correlated with that of $\beta 1$ integrin. It was also found that pseudopodium is more readily visible in $\mathrm{C} / \mathrm{S}$ outward edge than that in $\mathrm{C} / \mathrm{N}$, but hard to be visualized in inward edge regardless of $\mathrm{C} / \mathrm{S}$ or $\mathrm{C} / \mathrm{N}$ (Fig. 4e).

\section{PI3K and ERK1/2 signaling participates in $\beta 1$ integrin-mediated HaCaT migration}

We also tested the downstream signaling pathways that are associated with cell migration. For example, PI3Ks are involved in many cellular functions such as cell growth, motility, survival, and intracellular trafficking [37]. In the current work, it was found that PI3K expression for co-cultured WT-HaCaT cells was significantly enhanced at $1 \mathrm{~h}$ followed by a decrease or fluctuation, whereas it almost retained the same level without 


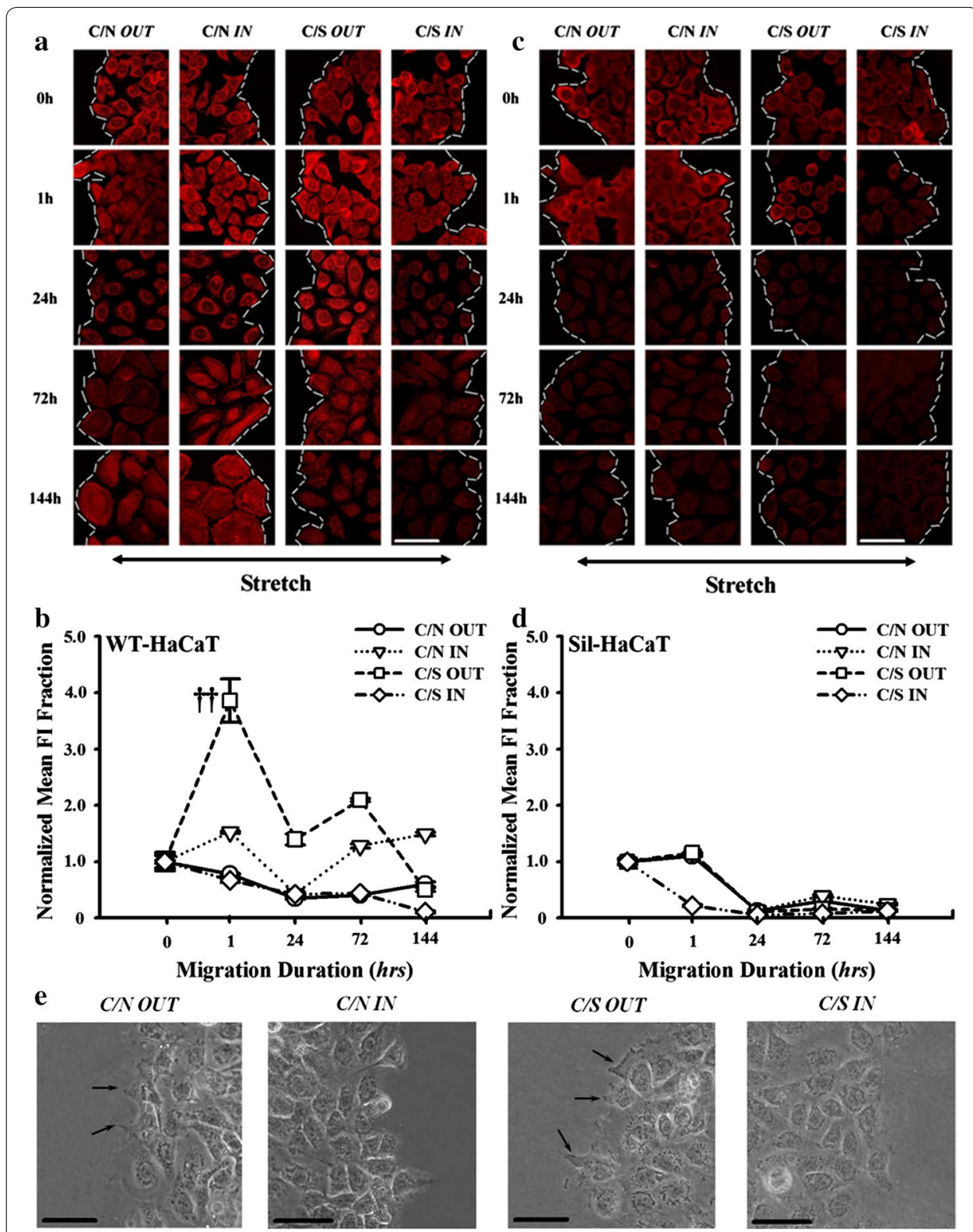

Fig. 4 Expression of $\mathrm{Cdc} 42$ in WT- and Sil-HaCaT cells in four migration patterns at different time points. a, b IF images and time courses of Cdc42 expression in WT-HaCaT cells $(\mathbf{a})$. Data were presented as the mean \pm SE of normalized $\mathrm{Fl}$ of totally $>9$ cells at the leading edge. ${ }^{+\dagger}$ The level of statistical significance of difference in normalized mean $\mathrm{Fl}$ at $t=1 \mathrm{~h}$ between C/S IN and C/S OUT patterns in WT-HaCaT cells (b). $\mathbf{c}, \mathbf{d}$ IF images and time courses of $\mathrm{Cdc} 42$ expression in Sil-HaCaT cells $(\mathbf{c})$. Data were presented as the mean $\pm \mathrm{SE}$ of normalized Fl of totally $>9$ cells at the leading edge (d). e Optical images of pseudopodium formation in WT-HaCaT cells. Arrows indicate the pseudopodium at day 2. Scale bar $50 \mu \mathrm{m}$

stretch. Importantly, the stretch-induced expression at the outward edge (squares) is dramatically higher than that at the inward leading edge (diamonds) $(P=0.0429)$, indicating that $\mathrm{HaCaT}$ cells prefer to migrate to the outward end due to the up-regulation of PI3K. By contrast, no differences were found at the inward (triangles) and outward (cycles) edges under non-stretch $(P=0.916)$, all of which are significantly lower than those under stretch, respectively (Fig. 5a, b). These results indicated that the 


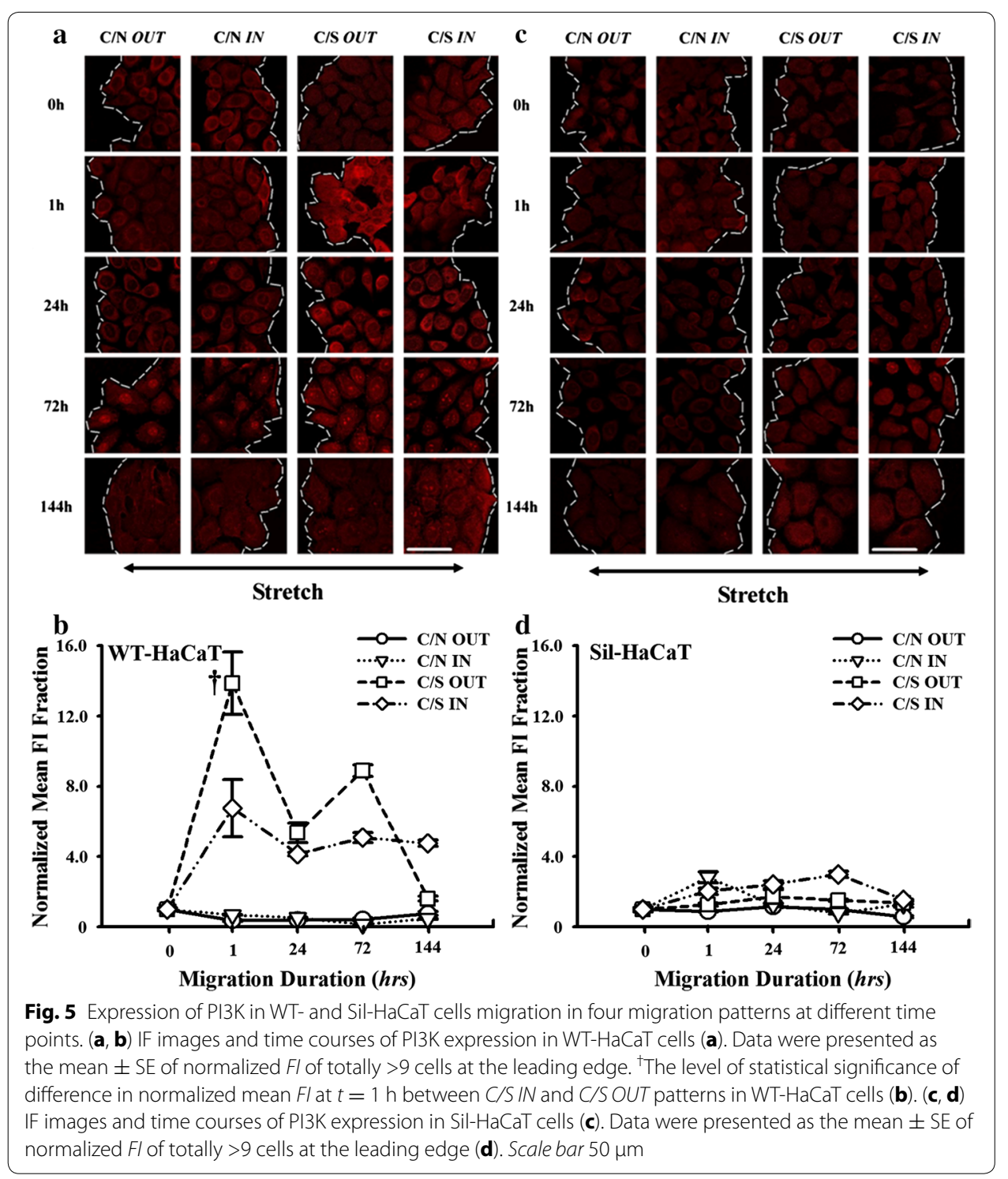

up-regulation of PI3K expression is mechanically-dependent and that the asymmetric presentation of PI3K molecules is positively correlated with the asymmetric migration under stretch. Conversely, no differences were observed between outward and inward edges for Sil-HaCaT cells under stretch or non-stretch (Fig. 5c, d), suggesting that the function of PI3K is well correlated with the presence of $\beta 1$ integrin.

Activation of ERK1/2 pathway via $\beta 1$ integrin, a well-known signaling, was also tested here for co-cultured WT- and Sil-HaCaT cells with or without mechanical stretch. Phosphorylated ERK1/2 expression in WT-HaCaT of C/S condition was altered obviously compared to that of $\mathrm{C} / \mathrm{N}$, especially at $24 \mathrm{~h}$. Importantly, the stretch-induced expression at the outward edge (squares) is higher than that at the inward leading edge (diamonds) $(P=0.002)$, indicating that $\mathrm{HaCaT}$ cells prefer to migrate to the outward end due to activating ERK1/2. By contrast, no differences were found at the inward (triangles) and outward (cycles) edges under non-stretch $(P=0.307)$, all of which are lower than those under stretch, respectively (Fig. 6a, b). These results indicated that the up-regulation of 


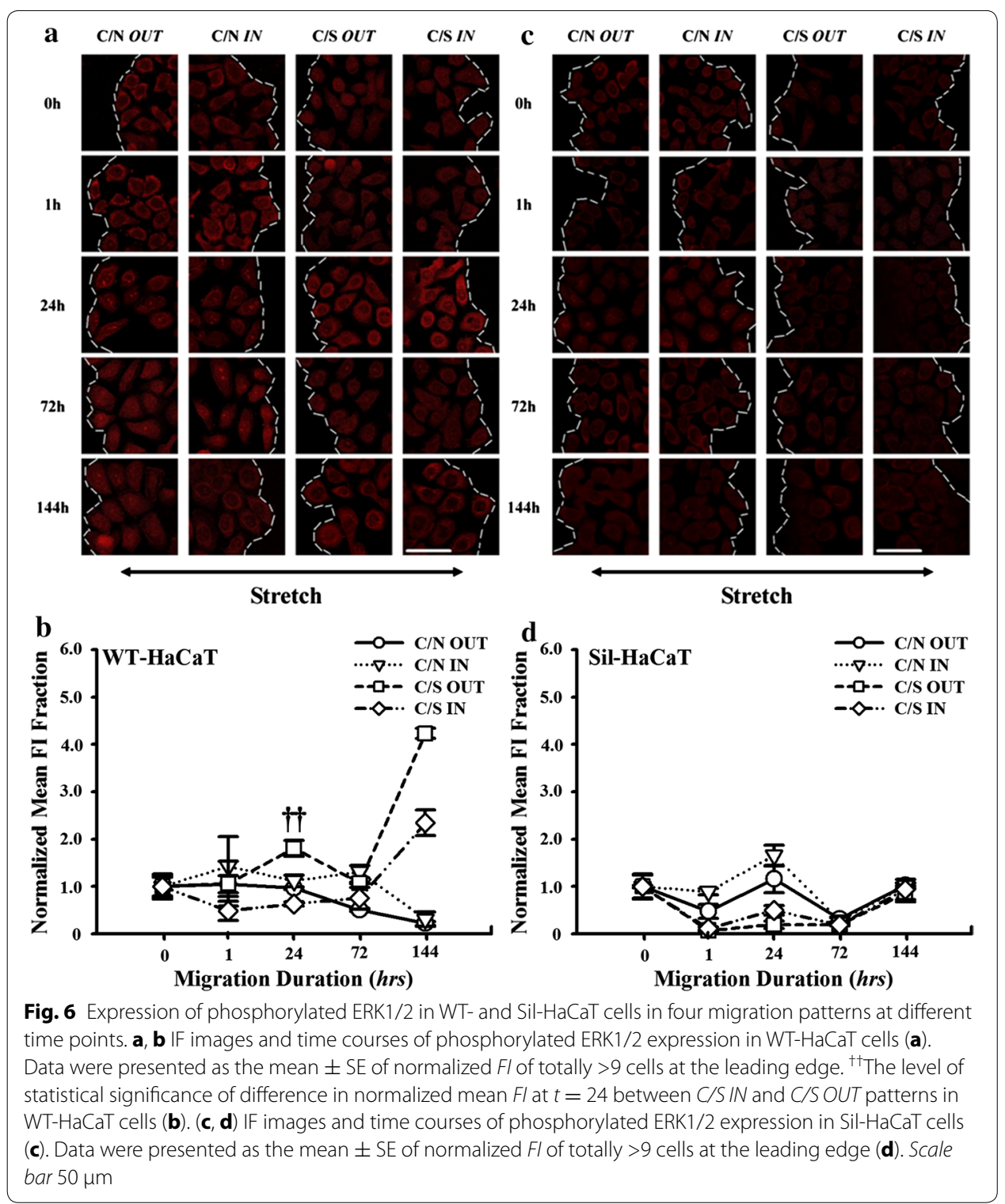

phosphorylated ERK1/2 expression is mechanically-dependent and that the asymmetric presentation of phosphorylated ERK $1 / 2$ is positively correlated with the asymmetric migration under stretch. Conversely, no differences were observed between outward and inward edges for Sil-HaCaT cells under stretch or non-stretch (Fig. 6c, d). These results suggested that the capability of ERK1/2 mechanosensing and phosphorylation is reduced dramatically after $\beta 1$ integrin knockdown. The activation of ERK1/2 is well correlated with the presence of $\beta 1$ integrin.

\section{Discussion}

The goal of the current work is to understand the dynamics of molecular mechanisms in keratinocyte migration under mechanical stimuli and co-cultured fibroblasts in wound repair model. Upon an in-house developed device of mechanical stretch, the capacity 
of $\mathrm{HaCaT}$ migration is asymmetric and prefers to migrate outwards, which is mainly governed by EGF factor mainly secreted by HF cells under mechanical stretch [16]. In the current work, those signaling proteins in asymmetric migration of $\mathrm{HaCaT}$ cells onto collagen I-coated substrate was directly visualized under mechanical stretch and in the presence of co-cultured HF cells. Cell signaling via collagen I- $\beta 1$ integrin-vinculin pathway plays a pivotal role in mediating the keratinocytes migration. Downstream transduction of Cdc42, PI3K, and ERK1/2 phosphorylation was positively correlated with the specified migration of keratinocytes, which are all $\beta 1$ integrin-dependent.

In fact, wound healing requires the cooperative interactions between different types of tissue and cell. The asymmetric migration of keratinocytes is the result of multiple interactions, including ECM, fibroblasts, and mechanical stretch, to affect the migration dynamics of skin keratinocytes. Since asymmetric migration might be an important behavior of cells to build tissues and organs (in epithelial cells to shape epithelial structures), here we revealed the interplay of specific molecular signaling pathways ( $\beta 1$ integrin, vinculin, Cdc42, PI3K, and ERK1/2) involved in asymmetric migration, this work is helpful to better understand how cells work for autonomic tissue or organ assembly.

It has been long noticed that the mechanical signals are able to transfer into cells via an outside-in signaling pathway, which is mainly composed of ECM-integrin-FACs [38]. Our results further supported that the collagen I- $\beta 1$ integrin-vinculin complex is most important molecules in mechanosensing of keratinocyte migration (Figs. 3, 4, 5 and 6). Here an important issue is why and how the static stretch, rather than the cyclic stretch, affects the cell migration. A cell is able to sense the deformation of elastic membrane initially and to reach the steady phase under a static stretch [39]. This interprets well why the early phase up-regulation was observed for the expressions of $\beta 1$ integrin and vinculin within the first hour of stretch onset (Fig. 3a, b).

Downstream mechanotransduction of mechanical signals is also crucial to induce the asymmetric migration of $\mathrm{HaCaT}$ cells. As one of the major protein kinases, PI3K play a crucial role in mediating the predominant outward migration at least in a rapid phase (Fig. 5), suggesting that PI3K activity is required for keratinocyte migration [40]. ERK1/2 phosphorylation has also been known as a mechanotransductive indicator for integrinbased cell attachments [41]. The enhancement of phosphorylated-ERK1/2 found in the current work supported that ERK1/2 is sensitive to mechanical stimuli that mediates keratinocyte migration via $\beta 1$ integrin (Fig. 6). Other signaling molecule, such as Rho GTPase Cdc42, is also contributed to the remodeling of actin cytoskeleton [42, 43]. High expression of Cdc42 is related to the formation of protrusive structures of the plasma membrane and formation of lamellipodia and filopodia [28]. It was also indicated that all the molecules of PI3K, ERK1/2, and Cdc42 are also dynamically activated in an early phase responses followed by a descending phase to a steady state, which is consistent with the dynamics of mechanosensing.

Migration and directed motility of keratinocytes on extracellular matrix components are known to go through $\beta 1$ integrin-dependent PI3K and ERK pathways by stabilizing lamellipodia at the leading edge of cells in re-epithelializing wounds [44, 45]. Activation and localization of Cdc42 proteins on cell membrane are involved in the cell podia formation in keratinocytes, which may facilitate cell migration to accelerate wound healing [46]. Thus, keratinocyte migration requires spatiotemporal integration of signaling 
molecules that regulate cell body motility. Our results further supported that mechanical stretch, as an important stimulator, is able to induce remarkable expressions of Cdc42, PI3K and ERK1/2 at the leading edge within $1 \mathrm{~h}$ for C/S OUT case. These alterations were decreased or even disappeared when $\beta 1$ integrins were knocked down (Figs. 4, 5 and 6). Meanwhile, cooperation of enhanced Cdc42 expression and pseudopodium formation for $\mathrm{C} / \mathrm{S}$ OUT case with increased vinculin expression for $\mathrm{C} / \mathrm{S}$ IN case enable $\mathrm{HaCaT}$ cells easier to adhere for $\mathrm{C} / \mathrm{S}$ IN case and to migrate along C/S OUT direction. Importantly, cell movement is orchestrated by a variety of membrane-anchored and intracellular signaling proteins including $\beta 1$ integrins, focal adhesion complex, Rho family of GTPases, PI3K and ERK1/2. These results provided, at least partially, the mechanotransductive mechanisms for asymmetric migration of $\mathrm{HaCaT}$ cells under mechanical stretch [16].

It was also noted in the current work that the presence of co-cultured HF cells are pre-requite for asymmetric migration of $\mathrm{HaCaT}$ cells, implying that the paracrine pathways of secreted growth factors by HF cells might be critical in regulating the migration dynamics $[16,47,48]$. While this topic is beyond the scope of the current work, it is worthwhile in the future work to understand the cross-talk of $\beta 1$ integrin and epidermal growth factor interactions [49] or transforming growth factor [50, 51] via MAPK and PI3K signal pathway, which are crucial in regulating keratinocyte motility and migration during wound repair. Taken together, a simple pathway was proposed for mechanicallyinduced signal transduction pathways for asymmetric migration of keratinocytes in this work.

\begin{abstract}
Abbreviations
ECM: extracellular matrix; ERK1/2: extracellular signal-regulated kinase; FAC: focal adhesion complex; HF: human fibroblast; IF: immunofluorescence; MAPK: mitogenesis-associated protein kinase; PI3K: phosphatidylinositol 3-kinase; RNAi: RNA interference; RT-PCR: reverse transcription-polymerase chain reaction; siRNA: small interfering RNA; VAC: vacuumassisted closure; WB: Western Blotting; C/N: co-culture and non-stretch; C/S: co-culture and stretch; IN: inward; OUT: outward.
\end{abstract}

\title{
Declarations
}

Authors' contributions

$M L$ and $D L$ developed the concept, designed the tests, and wrote the paper. $D L$ and $Z L$ performed the experiments. $\mathrm{DL}, \mathrm{CL}, \mathrm{FZ}, \mathrm{LZ}$ and JW analyzed the data. YG and SS designed and manufactured the device. All authors have made substantial contributions to conception and design, or acquisition of data, or analysis and interpretation of data and have been involved in drafting the manuscript or revising it critically for important intellectual content. Each author has participated sufficiently in the work to take public responsibility for appropriate portions of the content. All authors read and approved the final manuscript.

\section{Author details}

${ }^{1}$ Center of Biomechanics and Bioengineering, Institute of Mechanics, Chinese Academy of Sciences, Beijing 100190, China. ${ }^{2}$ Key Laboratory of Microgravity (National Microgravity Laboratory), Institute of Mechanics, Chinese Academy of Sciences, Beijing 100190, China. ${ }^{3}$ Beijing Key Laboratory of Engineered Construction and Mechanobiology, Institute of Mechanics, Chinese Academy of Sciences, Beijing 100190, China.

Acknowledgements

The authors thank Mr. Gang Peng for his technical assistance. This work was supported by National Natural Science Foundation of China Grants 31110103918, 31470907, 31000421, and 30730093; Strategic Priority Research Program grant XDA01030604

\section{Competing interests}

The authors declare that they have no competing interests.

\section{About this supplement}

This article has been published as part of BioMedical Engineering OnLine Volume 15 Supplement 2, 2016. Computational and experimental methods for biological research: cardiovascular diseases and beyond. The full contents of the supplement are available online http://biomedical-engineering-online.biomedcentral.com/articles/supplements/ volume-15-supplement-2. 
Availability of data and materials

All data are fully available without restriction.

\section{Funding}

Publication of this article was funded by National Natural Science Foundation of China Grants 31110103918 and 31470907.

Published: 28 December 2016

\section{References}

1. Singer AJ, Clark RAF. Mechanisms of disease—cutaneous wound healing. N Engl J Med. 1999;341:738-46.

2. Kirsner RS, Eaglstein WH. The wound healing process. Dermatol Clin. 1993;11:629-40.

3. Stadelmann WK, Digenis AG, Tobin GR. Physiology and healing dynamics of chronic cutaneous wounds. Am J Surg. 1998;176:26-38.

4. Gurtner GC, Werner S, Barrandon Y, Longaker MT. Wound repair and regeneration. Nature. 2008;453:314-21

5. Bartkova J, Gron B, Dabelsteen E, Bartek J. Cell-cycle regulatory proteins in human wound healing. Arch Oral Biol. 2003:48:125-32.

6. Li J, Chen J, Kirsner R. Pathophysiology of acute wound healing. Clin Dermatol. 2007;5:9-18.

7. Bandyopadhyay B, Fan J, Guan S, Li Y, Chen M, Woodley DT, Li W. A "traffic control"role for TGF beta3: orchestrating dermal and epidermal cell motility during wound healing. J Cell Biol. 2006;172:1093-105.

8. Nickoloff BJ, Mitra RS, Riser BL, Dixit VM, Varani J. Modulation of keratinocyte motility. Correlation with production of extracellular matrix molecules in response to growth promoting and antiproliferative factors. Am J Pathol. 1988;132:543-51.

9. El-Ghalbzouri A, Gibbs S, Lamme E, Van Blitterswijk CA, Ponec M. Effect of fibroblasts on epidermal regeneration. Br J Dermatol. 2002;147:230-43.

10. Tomasek JJ, Gabbiani G, Hinz B, Chaponnier C, Brown RA. Myofibroblasts and mechano-regulation of connective tissue remodelling. Nat Rev Mol Cell Biol. 2002;3:349-63.

11. Urschel JD, Scott PG, Williams HT. The effect of mechanical stress on soft and hard tissue repair; a review. Br J Plast Surg. 1988;41:182-6.

12. Chiquet M. Regulation of extracellular matrix gene expression by mechanical stress. Matrix Biol. 1999;18:417-26.

13. Argenta LC, Morykwas MJ. Vacuum-assisted closure: a new method for wound control and treatment: clinical experience. Ann Plast Surg. 1997;38:563-76.

14. Morykwas MJ, Simpson J, Punger K, Argenta A, Kremers L, Argenta J. Vacuum-assisted closure: state of basic research and physiologic foundation. Plast Reconstr Surg. 2006;117:121S-6S.

15. Orgill DP, Manders EK, Sumpio BE, Lee RC, Attinger CE, Gurtner GC, Ehrlich HP. The mechanisms of action of vacuum assisted closure: more to learn. Surgery. 2009;146:40-51.

16. Lü DY, Liu XF, Gao YX, Huo B, Kang YY, Chen J, Sun SJ, Chen L, Luo XD, Long M. Asymmetric migration of human keratinocytes under mechanical stretch and co-cultured fibroblasts in a wound repair model. PLOS ONE. 2013:8:e74563.

17. Humphries JD, Byron A, Humphries MJ. Integrin ligands at a glance. J Cell Sci. 2006;119:3901-3.

18. Kong F, Li ZH, Parks WM, Dumbauld DW, García AJ, Mould AP, Humphries MJ, Zhu C. Cyclic mechanical reinforcement of integrin-ligand interactions. Mol Cell. 2013;49:1060-8.

19. Brakebusch C, Fassler R. $\beta 1$ integrin function in vivo: adhesion, migration and more. Cancer Metast Rev. 2005;24:403-11.

20. Grose R, Hutter C, Bloch W, Thorey I, Watt FM, Fässler R, Brakebusch C, Werner S. A crucial role of beta 1 integrins for keratinocyte migration in vitro and during cutaneous wound repair. Development. 2002;129:2303-15.

21. Lal H, Verma SK, Smith M, Guleria RS, Lu G, Foster DM, Dostal DE. Stretch-induced MAP kinase activation in cardiac myocytes: differential regulation through $\beta 1$-integrin and focal adhesion kinase. J Mol Cell Cardiol. 2007:43:137-47.

22. Jalali S, del Pozo MA, Chen K, Miao H, Li Y, Schwartz MA, Shyy JY, Chien S. Integrin-mediated mechanotransduction requires its dynamic interaction with specific extracellular matrix (ECM) ligands. Proc Natl Acad Sci USA. 2001;98:1042-6.

23. Li J, Zhao ZH, Wang J, Chen GP, Yang JY, Luo SJ. The role of extracellular matrix, integrins, and cytoskeleton in mechanotransduction of centrifugal loading. Mol Cell Biochem. 2008;309:41-8.

24. Miyamoto S, Teramoto H, Gutkind JS, Yamada KM. Integrins can collaborate with growth factors for phosphorylation of receptor tyrosine kinases and MAP kinase activation: roles of integrin aggregation and occupancy of receptors. J Cell Biol. 1996;135:1633-42.

25. Matsubayashi Y, Ebisuya M, Honjoh S, Nishida E. ERK activation propagates in epithelial cell sheets and regulates their migration during wound healing. Curr Biol. 2004;14:731-5.

26. Jeong HW, Kim IS. TGF-beta1 enhances betaig-h3-mediated keratinocyte cell migration through the alpha3beta1 integrin and PI3K. J Cell Biochem. 2004;92:770-80.

27. Katsumi A, Naoe T, Matsushita T, Kaibuchi K, Schwartz MA. Integrin activation and matrix binding mediate cellular responses to mechanical stretch. J Biol Chem. 2005;280:16546-9.

28. Keely PJ, Westwick JK, Whitehead IP, Der CJ, Parise LV. Cdc42 and Rac1 induce integrin-mediated cell motility and invasiveness through PI(3)K. Nature. 1997;390:632-6.

29. Choma DP, Pumiglia K, DiPersio CM. Integrin alpha 3 beta 1 directs the stabilization of a polarized lamellipodium in epithelial cells through activation of Rac1. J Cell Sci. 2004;117:3947-59. 
30. Ciobanasu C, Faivre B, Le Clainche C. Integrating actin dynamics, mechanotransduction and integrin activation: the multiple functions of actin binding proteins in focal adhesions. Eur J Cell Biol. 2013;92(10-11):339-48.

31. Jockusch BM, Bubeck P, Giehl K, Kroemker M, Moschner J, Rothkegel M, Rüdiger M, Schlüter K, Stanke G, Winkler J. The molecular architecture of focal adhesions. Annu Rev Cell Dev Biol. 1995;11:379-416.

32. Albuquerque ML, Flozak AS. Lamellipodial motility in wounded endothelial cells exposed to physiologic flow is associated with different patterns of beta1-integrin and vinculin localization. J Cell Physiol. 2003;195:50-60.

33. Askari JA, Tynan CJ, Webb SE, Martin-Fernandez ML, Ballestrem C, Humphries MJ. Focal adhesions are sites of integrin extension. J Cell Biol. 2010;188:891-903.

34. Nelson WJ. Adaptation of core mechanisms to generate cell polarity. Nature. 2003;422:766-74.

35. Ridley AJ, Schwartz MA, Burridge K, Firtel RA, Ginsberg MH, Borisy G, Parsons JT, Horwitz AR. Cell migration: integrating signals from front to back. Science. 2003;302:1704-9.

36. Lämmermann T, Renkawitz J, Wu X, Hirsch K, Brakebusch C, Sixt M. Cdc42-dependent leading edge coordination is essential for interstitial dendritic cell migration. Blood. 2009;113:5703-10.

37. Vanhaesebroeck B, Guillermet-Guibert J, Graupera M, Bilanges B. The emerging mechanisms of isoform-specific PI3K signalling. Nat Rev Mol Cell Biol. 2010;1:329-41.

38. Giancotti FG, Ruoslahti E. Integrin signaling. Science. 1999;285:1028-32.

39. Arulmoli J, Pathak MM, McDonnell LP, Nourse JL, Tombola F, Earthman JC, Flanagan LA. Static stretch affects neural stem cell differentiation in an extracellular matrix-dependent manner. Sci Rep. 2015;5:8499.

40. Jiménez C, Portela RA, Mellado M, Rodríguez-Frade JM, Collard J, Serrano A, Martínez-A C, Avila J, Carrera AC. Role of the PI3K regulatory subunit in the control of actin organization and cell migration. J Cell Biol. 2000;151:249-62.

41. Plotkin LI, Mathov I, Aguirre JI, Parfitt AM, Manolagas SC, Bellido T. Mechanical stimulation prevents osteocyte apoptosis: requirement of integrins, Src kinases, and ERKs. Am J Physiol Cell Physiol. 2005;289:C633-43.

42. Van Aelst L, D'SouzaSchorey C. Rho GTPases and signaling networks. Genes Dev. 1997;11:2295-322.

43. Schoenwaelder SM, Burridge K. Bidirectional signaling between the cytoskeleton and integrins. Curr Opin Cell Biol. 1999;11:274-86.

44. Watson A, Morris VL, Chan BM. Coordinated integrin and growth factor regulation of primary keratinocyte migration mediated through extracellular signal regulated kinase and phosphoinositide 3-kinase. Arch Dermatol Res. 2009;4:307-17.

45. Löffek S, Hurskainen T, Jackow J, Sigloch FC, Schilling O, Tasanen K, Bruckner-Tuderman L, Franzke CW. Transmembrane collagen XVII modulates integrin dependent keratinocyte migration via PI3K/Rac1 signaling. PLOS ONE. 2014;2:e87263.

46. Hsu CC, Chow SE, Chen CP, Tsai WC, Wang JS, Yu SY, Lee SC. Negative pressure accelerated monolayer keratinocyte healing involves Cdc42 mediated cell podia formation. J Dermatol Sci. 2013:3:196-203.

47. Raja, Sivamani K, Garcia MS, Isseroff RR. Wound re-epithelialization: modulating keratinocyte migration in wound healing. Front Biosci. 2007;12:2849-68.

48. Smola H, Thiekotter G, Fusenig NE. Mutual induction of growth factor gene expression by epidermal-dermal cell interaction. J Cell Biol. 1993;122:417-29.

49. Moro L, Venturino M, Bozzo C, Silengo L, Altruda F, Beguinot L, Tarone G, Defilippi P. Integrins induce activation of EGF receptor: role in MAP kinase induction and adhesion-dependent cell survival. EMBO J. 1998;17:6622-32.

50. Schultz G, Rotatori DS, ClarkW. EGF and TGF-alpha in wound healing and repair. J Cell Biochem. 1991:45:346-52

51. Li Y, Fan JH, Chen M, Li W, Woodley DT. Transforming growth factor-alpha: a major human serum factor that promotes human keratinocyte migration. J Invest Dermatol. 2006;126:2096-105.

Submit your next manuscript to BioMed Central and we will help you at every step:

- We accept pre-submission inquiries

- Our selector tool helps you to find the most relevant journal

- We provide round the clock customer support

- Convenient online submission

- Thorough peer review

- Inclusion in PubMed and all major indexing services

- Maximum visibility for your research

Submit your manuscript at www.biomedcentral.com/submit 